Document downloaded from:

http://hdl.handle.net/10251/149539

This paper must be cited as:

Benajes, J.; García Martínez, A.; Monsalve-Serrano, J.; Boronat-Colomer, V. (2017).

Achieving clean and efficient engine operation up to full load by combining optimized RCCI and dual-fuel diesel-gasoline combustion strategies. Energy Conversion and Management. 136:142-151. https://doi.org/10.1016/j.enconman.2017.01.010

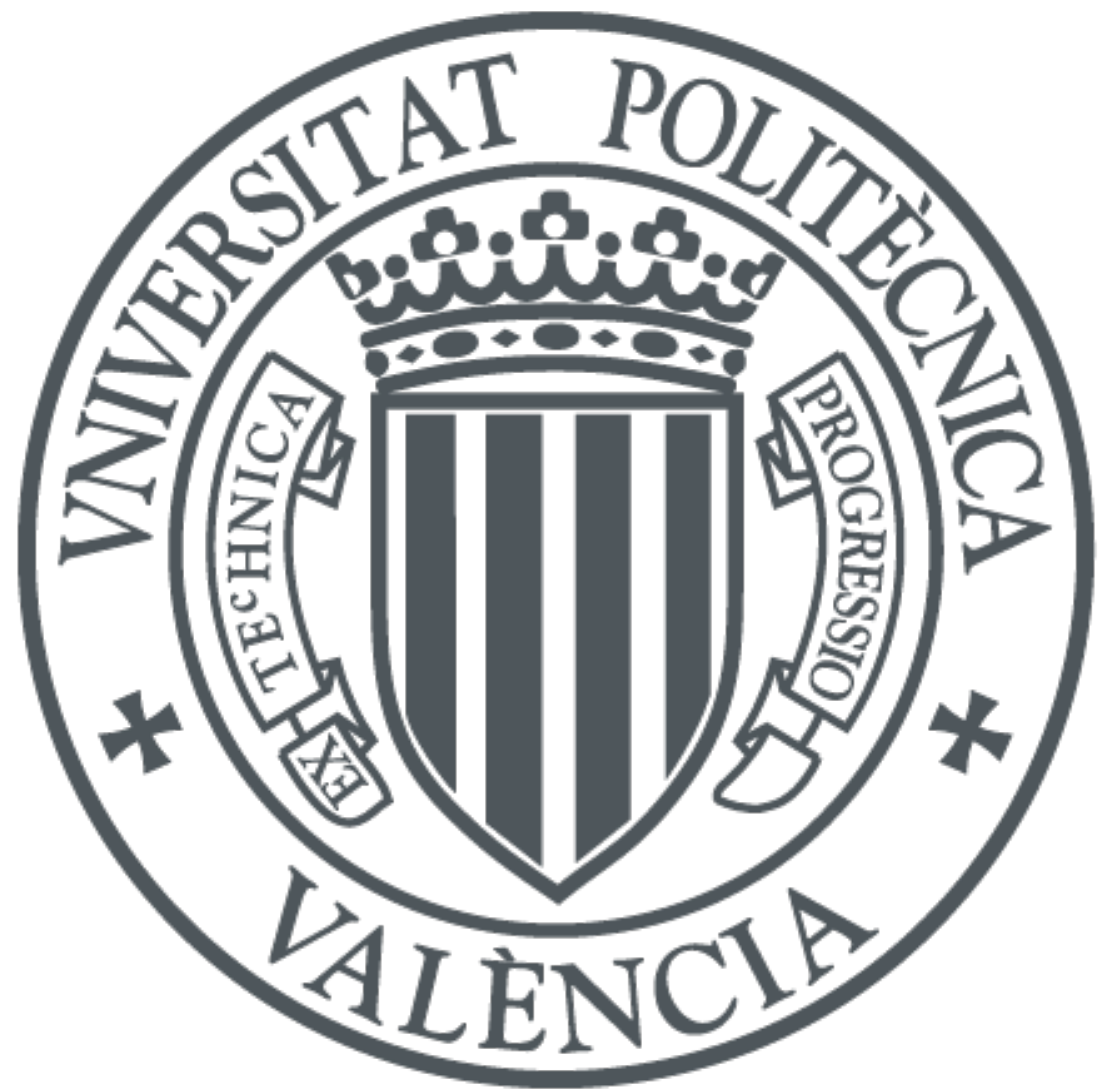

The final publication is available at

https://doi.org/10.1016/j.enconman.2017.01.010

Copyright Elsevier

Additional Information 


\title{
Achieving clean and efficient engine operation up to full load by combining optimized RCCl and dual-fuel diesel-gasoline combustion strategies
}

Energy Conversion and Management, Volume 136, 15 March 2017, Pages 142-151. http://dx.doi.org/10.1016/j.enconman.2017.01.010

\section{Jesús Benajes, Antonio García*, Javier Monsalve-Serrano and Vicente Boronat \\ CMT - Motores Térmicos, Universitat Politècnica de València, Camino de Vera s/n, 46022 Valencia, Spain}

Corresponding author $(*)$ :

Dr. Antonio García (angarma8@mot.upv.es)

Phone: +34 963879659

Fax: +34963877659

\begin{abstract}
This experimental work investigates the capabilities of the reactivity controlled compression ignition combustion concept to be operated in the whole engine map and discusses its benefits when compared to conventional diesel combustion. The experiments were conducted using a single-cylinder medium-duty diesel engine fueled with regular gasoline and diesel fuels. The main modification on the stock engine architecture was the addition of a port fuel injector in the intake manifold. In addition, with the aim of extending the reactivity controlled compression ignition operating range towards higher loads, the piston bowl volume was increased to reduce the compression ratio of the engine from 17.5:1 (stock) down to 15.3:1.
\end{abstract}

To allow the dual-fuel operation over the whole engine map without exceeding the mechanical limitations of the engine, an optimized dual-fuel combustion strategy is proposed in this research. The combustion strategy changes as the engine load increases, starting from a fully premixed reactivity controlled compression ignition combustion up to around 8 bar IMEP, then switching to a highly premixed reactivity controlled compression ignition combustion up to 15 bar IMEP, and finally moving to a mainly diffusive dual-fuel combustion to reach the full load operation. The engine mapping results obtained using this combustion strategy show that reactivity controlled compression ignition combustion allows fulfilling the EURO VI NOx limit up to 14 bar IMEP. Ultra-low soot emissions are also achieved when the fully premixed combustion is promoted, however, the soot levels rise notably as the combustion strategy moves to a less premixed pattern. Finally, the direct comparison of reactivity controlled compression ignition versus conventional diesel combustion using the nominal engine settings, reveals that reactivity controlled compression ignition can be a potential solution to reduce the selective catalyst reduction and diesel particulate filter aftertreatment necessities with a simultaneous improving of the thermal efficiency.

\section{Keywords}

Reactivity controlled compression ignition; Dual-fuel combustion; Engine map; EURO VI emissions; Efficiency 


\section{Introduction}

The stringent emissions standards introduced for internal combustion engines suppose a major challenge for the research community. The technological solution adopted by the manufactures of diesel engines to meet the NOx and particulate matter values imposed in the EURO VI regulation relies on using selective catalyst reduction (SCR) [1] and diesel particulate filter (DPF) systems [2], which increases the complexity and cost of the engine. Alternatively, several new combustion modes aimed at avoiding the formation of these two pollutants by promoting low temperature combustion (LTC) reactions, are in focus of study nowadays [3]. In this sense, homogeneous charge compression ignition $(\mathrm{HCCl})$ has demonstrated great potential to inhibit the emission of these two pollutants while maintaining high efficiency [4][5]. However, low combustion control, high mechanical engine stress and excessive unburned products were identified with $\mathrm{HCCl}$ [6]. Some researchers suggested that to promote a proper $\mathrm{HCCl}$ operation, the in-cylinder reactivity must vary depending on the engine operating conditions, which could be achieved using high cetane fuels at low load and low cetane fuels at mediumhigh load [7]. Moreover, several other techniques aimed at modulating the in-cylinder reactivity such as the residual gas trapping [8], valve lift optimization [9], variable valve timing [10] and fuel modification [11] were studied. These methods were found to be beneficial for reducing the $\mathrm{HCCl}$ shortcomings, but were not enough to enable a wide $\mathrm{HCCl}$ operating range. By this reason, the use of gasoline-like fuels under partially premixed combustion (PPC) strategies gained interest to be studied [12]. In this sense, several researchers confirmed the gasoline PPC as a promising strategy to improve the heat release control while reducing the NOx and soot emissions simultaneously [13][14]. However, the low load PPC operation using gasolines of octane number (ON) greater than 90 was found to be inadequate due to the excessive combustion instability [15][16]. Trying to solve this problem, some researchers investigated the use of a spark plug to assist the low load PPC operation. It was found that the spark discharge improves the control of the PPC combustion process, temporal [17] and spatially [18], over the low load gasoline PPC combustion process, but led to excessive NOx and soot emissions [19], even using double injection strategies [20][21].

Among the LTC combustion concepts, the dual-fuel strategy commonly known as reactivity controlled compression ignition ( $\mathrm{RCCl}$ ) has the major scientific interest nowadays [22]. This strategy relies on injecting a low reactivity fuel in the intake port and a high reactivity fuel directly in-cylinder [23]. The $\mathrm{RCCl}$ combustion mode differs from the conventional dual-fuel combustion in that $\mathrm{RCCl}$ relies on decoupling the end of injection of the direct injected fuel and the start of combustion [24]. This promotes a well-mixed and dilute charge, which provides ultra-low NOx and soot emissions together with high efficiency over a wide range of engine speeds and loads [25]. In addition, RCCI concept allows better control of the combustion process than the single-fuel LTC strategies thanks to the capacity of modulating the fuel reactivity depending on the engine operating conditions [26]. The literature demonstrates that to attain these combustion characteristics, a highly premixed combustion strategy is necessary [27]. This is typically done using a double injection diesel pulse, with the first injection at around -60 to -40 CAD ATDC and the second one at around -35 CAD ATDC [28]. The first injection was found to be necessary to improve the in-cylinder reactivity in the crevices zones, where high amount of gasoline gets trapped [29]. The second diesel injection is 
needed to act as an ignition source, and should be relatively advanced to have enough mixing time to avoid soot formation [30]. In spite of these benefits, this type of injection strategy results in excessive maximum pressure rise rate (PRR) and maximum in-cylinder pressure $\left(P_{\max }\right)$ when increasing the engine load, which limits the maximum engine load achievable with RCCl operation [31]. This occurs because the in-cylinder charge comped of homogeneously mixed gasoline and highly premixed diesel (from the first injection) autoignites abruptly when the main diesel pulse is injected [32].

In order to extend the engine operation up to full load without exceeding the engine mechanical limits, a switch to conventional diesel combustion (CDC) can be done [33]. This solution, commonly known as dual-mode engine operation, showed a promising potential for reducing the aftertreatment necessities in terms of exhaust fluids (urea and diesel) consumption. However, the need for a high compression ratio to ensure high efficiency when running in CDC mode, resulted in a dramatic reduction of the effective $\mathrm{RCCl}$ operating range [34]. This fact rests potential to the concept and questions the advantages of moving from CDC to a dual-fuel architecture. Another possible solution to allow the operation in all the engine map could be the modification of the dual-fuel injection/combustion strategy to avoid the excessive PRR and $P_{\max }$ as engine load increases, which can be done moving from a highly premixed dual-fuel strategy (RCCI) to a less premixed strategy progressively. Although this method entails penalizing the NOx and soot emissions as compared to a highly premixed RCCl strategy, the capabilities of this alternative versus CDC must be studied in detail. Thus, the present investigation aims at evaluating the potential of this solution, in which dual-fuel operation is achieved over the whole engine map using different injection strategies. To do this, firstly, a dedicated testing procedure is defined to obtain engine maps that are used to analyze the performance and engine-out emissions of the dual-fuel combustion strategy proposed. Later, a direct comparison between dual-fuel and conventional diesel combustion operation is presented by means of engine maps differences, which allows to extract the main advantages and drawbacks of the combustion mode under investigation.

\section{Materials and methods}

\subsection{Test cell characteristics and engine description}

The tests performed in this study were carried out in a single-cylinder engine which comes from a medium-duty stock engine. In addition, the engine satisfies the newest EURO VI limitations and was specially developed for urban freight distribution purposes. As shown in Table 1, the nominal compression ratio (CR) of the production engine is 17.5:1. Previous studies showed that, with this $\mathrm{CR}$, the $\mathrm{RCCl}$ operation is limited to a narrow region between $25 \%$ and $35 \%$ load, even using a mid-level ethanol blend (E2095) as a low reactivity fuel [35]. In a further study, it was found that the $\mathrm{RCCl}$ operating range can be extended up to $80 \%$ load by reducing the CR to 12.75 , however the region below $25 \%$ load showed lower efficiency than CDC [36]. Thus, in the present study, an intermediate $C R$ of 15.3:1 was set in the engine by increasing the bowl volume as compared to the stock piston (Figure 1). The bowl geometry for the RCCl piston was defined following the guidelines provided in literature [37][38], which suggests that wider bowl geometries with lower surface areas are beneficial to increase the efficiency of the RCCl concept [39]. This is explained due to both, the lower heat transfer and the enhanced burning of the gasoline located at the crevice region. The lower heat transfer 
is consequence of the lower area-to-volume ratio and the enhanced gasoline burning results from the better flow of the high temperature gas until the crevice zone [29].

Table 1. Engine characteristics.

\begin{tabular}{|l|l|}
\hline Style & 4 Stroke, 4 valves, DI diesel engine \\
\hline Manufacturer / model & VOLVO / D5K240 \\
\hline OEM ECU calibration & EURO VI \\
\hline Maximum power & $177 \mathrm{~kW} @$ 2200 rpm \\
\hline Maximum brake torque & $900 \mathrm{Nm} @ 1200-1600 \mathrm{rpm}$ \\
\hline Maximum in-cylinder pressure & $190 \mathrm{bar}$ \\
\hline Bore x Stroke & $110 \mathrm{~mm} \times 135 \mathrm{~mm}$ \\
\hline Connecting rod length & $212.5 \mathrm{~mm}$ \\
\hline Crank length & $67.5 \mathrm{~mm}$ \\
\hline Total displaced volume & $5100 \mathrm{~cm}^{3}$ \\
\hline Number of cylinders & 4 \\
\hline Compression ratio (nominal) & $17.5: 1$ \\
\hline Compression ratio for RCCI & $15.3: 1$ \\
\hline
\end{tabular}

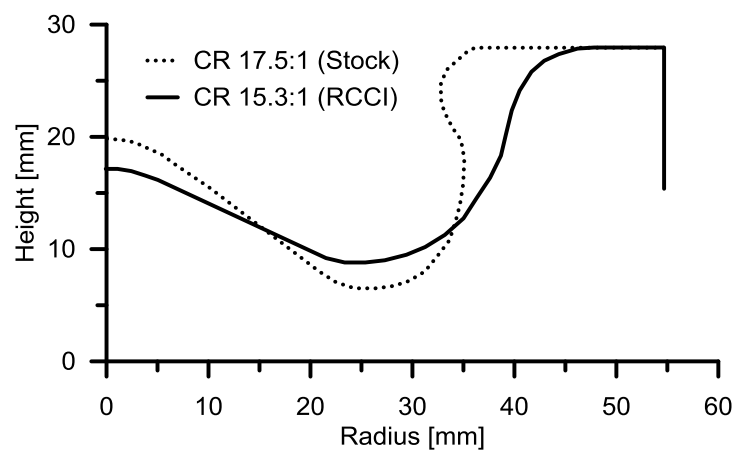

Figure 1. Cross sectional view of the stock (CR 17.5:1) and RCCI (CR 15.3:1) piston geometries.

In order to operate the engine under RCCl mode, the engine was modified by adding an additional injection system, as it is observed in Figure 2. Therefore, it is possible to modify the properties of the fuel blend and fuel mixture depending on the operating conditions. For this purpose, single-cylinder engine (SCE) operation was carried out by an in-house controller based in Drivven systems for the correct acquisition and injection control, replacing the function of the original engine manufacturer (OEM) electronic control unit (ECU), allowing full control of the direct injection (DI) and port fuel injection (PFI) parameters.

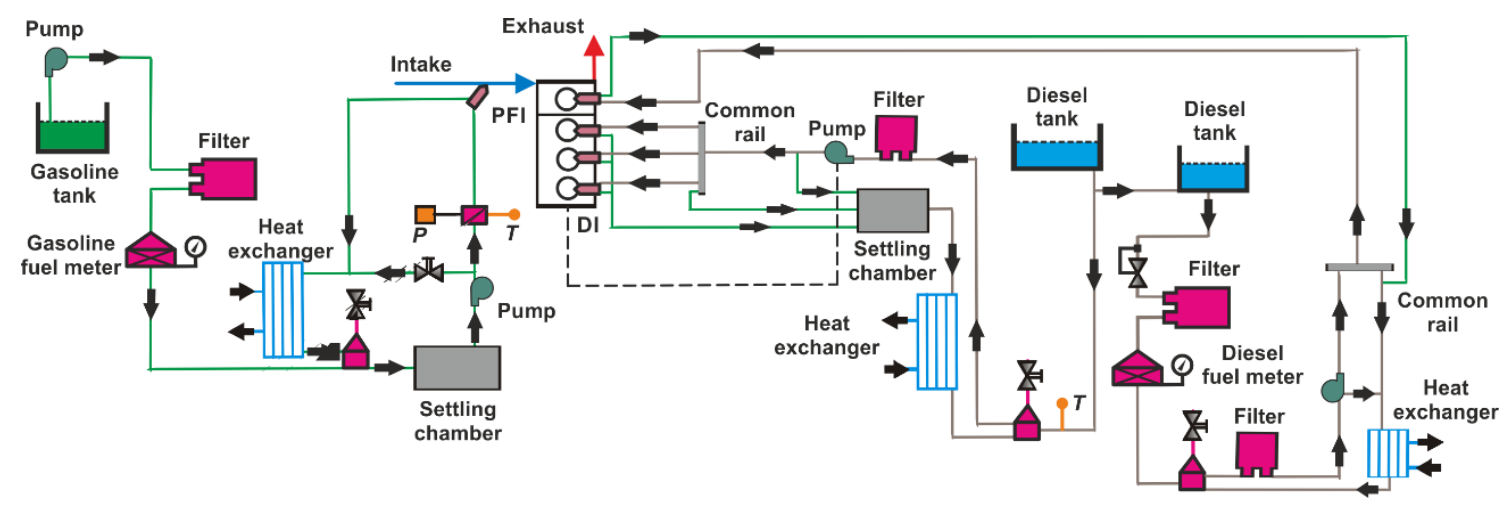


Figure 2. Fuel injection systems scheme.

The high and low reactivity fuels used were regular diesel and 95 octane number gasoline, respectively. Their main properties are listed in Table 2. All the properties were obtained following American society for testing and materials (ASTM) standards.

Table 2. Physical and chemical properties of the fuels.

\begin{tabular}{|l|c|c|}
\cline { 2 - 3 } \multicolumn{1}{c|}{} & Diesel & Gasoline \\
\hline Density $\left[\mathrm{kg} / \mathrm{m}^{3}\right]\left(\mathrm{T}=15^{\circ} \mathrm{C}\right)$ & 824 & 720 \\
\hline Viscosity $\left[\mathrm{mm}^{2} / \mathrm{s}\right]\left(\mathrm{T}=40^{\circ} \mathrm{C}\right)$ & 2.8 & - \\
\hline RON [-] & - & 95 \\
\hline MON [-] & - & 85 \\
\hline Biodiesel content [\% by volume] & $<0.2$ & - \\
\hline Cetane number [-] & 51 & - \\
\hline Lower heating value $[\mathrm{kJ} / \mathrm{kg}]$ & 42.92 & 42.4 \\
\hline
\end{tabular}

The engine was equipped with a common-rail injection hardware which is in charge of the direct diesel injection. The injector and nozzle main properties are presented in Table 3.

Table 3. Characteristics of the high reactivity fuel injector.

\begin{tabular}{|l|c|}
\hline Actuation Type & Solenoid \\
\hline Steady flow rate @ 100 bar $\left[\mathrm{cm}^{3} / \mathrm{min}\right]$ & 1300 \\
\hline Number of Holes & 7 \\
\hline Hole diameter $[\mu \mathrm{m}]$ & 177 \\
\hline Included Spray Angle $\left[^{\circ}\right]$ & 150 \\
\hline Maximum injection pressure [bar] & 2000 \\
\hline
\end{tabular}

The second fuel injection system was in charge of injecting the gasoline. The whole injection system was developed in-house, except the elements commercially available such as the PFI. The circuit consists of a fuel pump, a fuel tank, fuel filter and the mentioned injector. The PFI was placed at the intake manifold once it was ensured its capabilities in order to supply the total amount of gasoline during the intake stroke. Avoid fuel pooling at the intake valves was the main target due to the variability produced by this phenomenon. Therefore, the injection timing was set 10 CAD after the intake valve opening (IVO) providing enough time for the gasoline to cover the distance between the injector and the valve seats. The main properties are shown in Table 4.

Table 4. Characteristics of the low reactivity fuel injector.

\begin{tabular}{|l|c|}
\hline Injector Style & Saturated \\
\hline Steady flow rate @ 3 bar $\left[\mathrm{cm}^{3} / \mathrm{min}\right]$ & 980 \\
\hline Included Spray Angle $\left[^{\circ}\right]$ & 30 \\
\hline Injection Pressure [bar] & 5.5 \\
\hline Injection Strategy & Single \\
\hline Start of Injection Timing & 340 CAD ATDC \\
\hline
\end{tabular}


The engine was installed in a fully instrumented test cell, equipped with the required equipment to operate and control the engine, as it is shown in Figure 3. The SCE differs from a regular research SCE. The solution adopted by the authors represents a hybrid set-up between a multi-cylinder engine and a research SCE [40]. This system allows operating an isolated cylinder as a SCE while the other three cylinders are governed by the stock ECU in order to equalize the cylinder-to-cylinder maximum load and pressure [41]. As a result, this hybrid SCE solution relies in a less cost effective option compared with the traditional research single cylinder engines and incorporates the advantage of enable the possibility to extend the scope of the study. On the other hand, it is not possible to obtain torque-based results for the isolated cylinder due to the crankshaft and the dynamometer is the same for both engines, resulting the measurements invalid. Nonetheless, the combustion process is studied by using indicated parameters avoiding thereby the limitations.

From Figure 3 it is possible to see that the multi-cylinder engine (MCE) is also fully instrumented, being monitored during the operation. In addition, the in-cylinder pressure is monitored in real time for both engines in order to equalize the engines. Concluding this part, just remark that the exhaust gas recirculation (EGR) loop from the MCE was removed to compensate the energy lost because of the isolated cylinder.

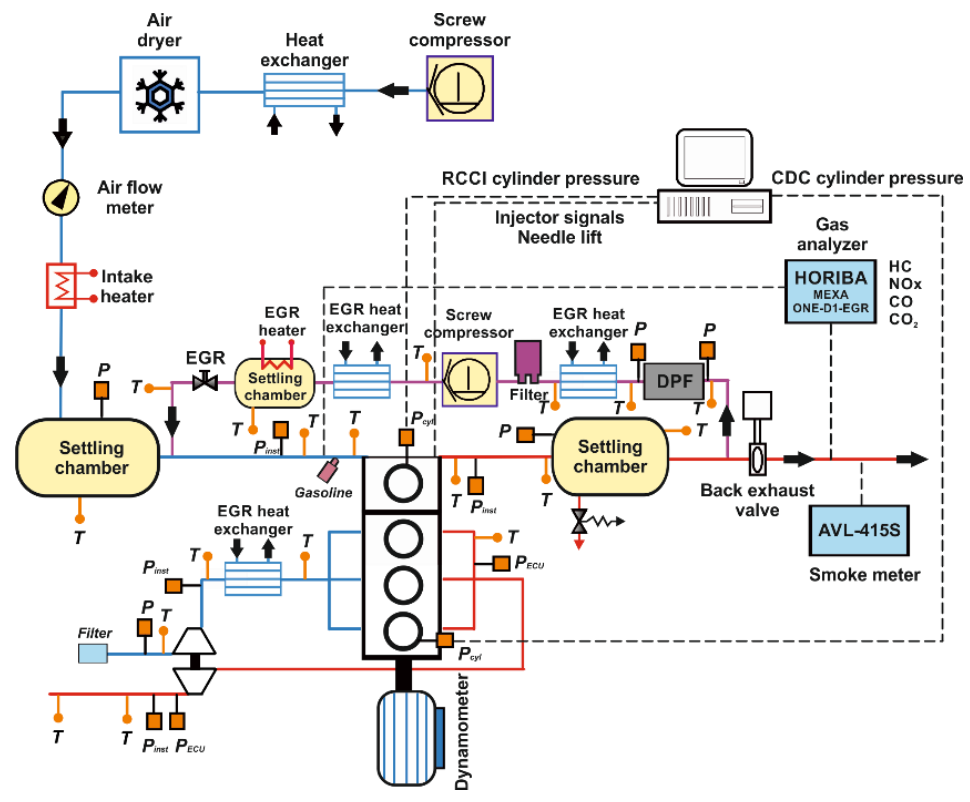

Figure 3. Test cell scheme.

Figure 3 shows all the elements required to isolate the cylinder under study, particularly for the air-loop. The air management must ensure stable intake air conditions along the engine map. Therefore, a screw compressor supplies the boosted air to the intake. Once the boost pressure is reached, the air is conditioned in terms of humidity and temperature. An air dryer and a heater adjust the air conditions continuously during the engine operation. In order to replicate the backpressure produced by the turbine, a valve is placed in the exhaust line controlling the pressure at the exhaust settling chamber. An additional air-loop is located in the test cell in charge of the EGR flow supply by means of low pressure EGR taken from the exhaust settling chamber. EGR rate was determined by using the experimental measurement of $\mathrm{CO}_{2}$ concentration at the exhaust and at the intake. The other emissions obtained experimentally at the test cell 
are $\mathrm{NOx}, \mathrm{O}_{2}$, unburned $\mathrm{HC}$ and $\mathrm{CO}$, and have been analyzed with a five gas Horiba MEXAONE-D1-EGR analyzer. This equipment averages the measurement of a 40 seconds sample while the operating point is completely steady. As it is stated in [42], the combustion efficiency is determined by using the $\mathrm{CO}$ and unburned $\mathrm{HC}$ measurements (Equation 1):

$$
\text { Comb. Eff }=\left(1-\frac{\mathrm{HC}}{\mathrm{mf}}-\frac{\mathrm{CO}}{4 \cdot \mathrm{mf}}\right) \cdot 100
$$

An AVL 415S Smoke Meter was used to measure the smoke emissions. The smoke Meter averages between three samples of a 1 liter volume each with paper-saving mode off. This equipment provides the results directly in Filter Smoke Number (FSN) units. The incylinder pressure signal was measured with a Kistler $6125 \mathrm{C}$ pressure transducer and its respective amplifier Kistler 5011B10. Finally, the crank angle position was obtained by using a shaft encoder with 1800 pulses per revolution, providing a resolution of 0.2 CAD. The accuracy of the instrumentation used in this work is summarized in Table 5.

Table 5. Accuracy of the instrumentation used in this work.

\begin{tabular}{|l|l|l|l|}
\hline Variable measured & Device & Manufacturer / model & Accuracy \\
\hline In-cylinder pressure & $\begin{array}{l}\text { Piezoelectric } \\
\text { transducer }\end{array}$ & Kistler / 6125C & \pm 1.25 bar \\
\hline Intake/exhaust pressure & $\begin{array}{l}\text { Piezorresistive } \\
\text { transducers }\end{array}$ & Kistler / 4045A10 & \pm 25 mbar \\
\hline $\begin{array}{l}\text { Temperature in settling } \\
\text { chambers and manifolds }\end{array}$ & Thermocouple & TC direct / type K & $\pm 2.5^{\circ} \mathrm{C}$ \\
\hline Crank angle, engine speed & Encoder & AVL / 364 & \pm 0.02 CAD \\
\hline NOx, CO, $\mathrm{HC}, \mathrm{O}_{2}, \mathrm{CO}_{2}$ & Gas analyzer & HORIBA / MEXA-ONE-D1-EGR & $4 \%$ \\
\hline FSN & Smoke meter & AVL / 415S & $\pm 0.025 \mathrm{FSN}$ \\
\hline $\begin{array}{l}\text { Gasoline/diesel fuel mass } \\
\text { flow }\end{array}$ & Fuel balances & AVL / 733S & $\pm 0.2 \%$ \\
\hline Air mass flow & Air flow meter & Elster / RVG G100 & $\pm 0.1 \%$ \\
\hline
\end{tabular}

\subsection{In-cylinder pressure signal processing}

The in-house developed one-zone model used to perform the combustion analysis, named CALMEC, is fully described in reference [43]. The combustion diagnosis tool uses the in-cylinder pressure signal from the engine experiments as a main input, but it also needs to be feed with other variables such as the engine speed, inlet and exhaust coolant and oil temperatures, air mass flow, EGR rate and fuel mass, among others.

The combustion diagnosis tool is fed with the pressure traces of 150 consecutive engine cycles for each operating point, which leads to analyze the cycle-to-cycle variation. The individual raw pressure data is smoothed using a Fourier series low-pass filter. After that, a representative cylinder pressure trace is obtained by averaging the collected cycles, which is used to perform the analysis. Thus, the first law of thermodynamics was applied between the intake valve closing (IVC) and exhaust valve opening (EVO), considering the combustion chamber as an open system because of the blow-by and fuel injection. The mean gas temperature in the chamber is calculated using the ideal 
gas equation of state. In addition, the gas thermodynamic conditions in the chamber are obtained through the in-cylinder pressure signal to feed the convective and radiative heat transfer models [44], as well as the filling and emptying model that provided the fluid-dynamic conditions in the ports, and the heat transfer flows in these elements. The convective and radiative models are linked to a lumped conductance model to calculate the wall temperatures.

The main results from the model used during the analysis shown in this work are the bulk gas temperature and the maximum in-cylinder pressure rise rate. In addition, the rate of heat release (RoHR) and some parameters derived from the RoHR analysis are used. In particular, the start of combustion (SOC) and the combustion phasing (CA50) are defined as the timing of the $5 \%$ and $50 \%$ cumulated heat release, respectively.

\section{Results and discussion}

The results of the current investigation are divided in three subsections. The first subsection is dedicated to explain the combustion strategy used to obtain the RCCl results. The second subsection shows the $\mathrm{RCCl}$ emissions and performance results in form of engine maps. Finally, the last subsection is dedicated to discuss the potential of the $\mathrm{RCCl}$ concept by performing a direct comparison with the CDC operation with the same engine configuration.

\subsection{Combustion strategy description}

Three different combustion strategies have been used to achieve the dual-fuel operation in the whole engine map. Mandatory constraints to define these combustion strategies were to ensure maximum pressure rise rates (PRR) and in-cylinder pressure peaks ( $P_{\max }$ ) below 15 bar/CAD and 190 bar, respectively. As shown in the engine map depicted in Figure 4, the switch between the different fueling strategies is merely defined by the engine load:

- From idle up to $40 \%$ load (around 8 bar IMEP), the combustion strategy can be defined as fully premixed. This combustion strategy is achieved using a double diesel injection pulse with highly advanced injection timings. Because of the high mixing time available before the start of combustion, ultra-low NOx and soot emissions are obtained. As a counterpart, the diesel injection timing has not much influence on the combustion phasing, which is basically governed by the fuel reactivity through the gasoline fraction. As shown in Figure 4, the fully premixed combustion is characterized by a Gaussian-shaped heat release of short duration and rapid expansion period, which explains the high efficiency of this strategy.

- From $40 \%$ up to $75 \%$ load (around 15 bar IMEP), the combustion strategy can be defined as highly premixed. This combustion strategy is also achieved using a double diesel injection pulse, but in this case with the second injection taking place in the vicinities of the top dead center (TDC). In this sense, the first injection is intended to improve the reactivity in the crevices zone, where high amount of gasoline gets trapped [30], while the second diesel injection during the high pressure and temperature instants of the cycle acts as an ignition source. Because of the less premixing time for the diesel injection that takes place near TDC, higher soot levels than with the fully premixed strategy are found, however it can be still achieved NOx emissions below the EURO VI limit. This strategy provides a higher 
degree of combustion control due to the partial diffusion burning, being the CA50 very sensitive to the second diesel injection.

- From $75 \%$ up to full load, the combustion strategy can be defined as diffusive. This combustion strategy is achieved using a single diesel injection with a delayed injection timing, which allows introducing the high amount of fuel needed to achieve the required load without exceeding the engine mechanical constraints (PRR and $\mathrm{P}_{\max }$ ). Even so, the combustion typically starts with a high RoHR peak due to the gasoline burning during the first diesel reactions. After this, the combustion event is characterized by a long diesel-like tail during the expansion stroke. Because of the diffusive nature of the combustion, high levels of soot emissions are obtained and NOx emissions cannot be maintained below the EURO VI limit.
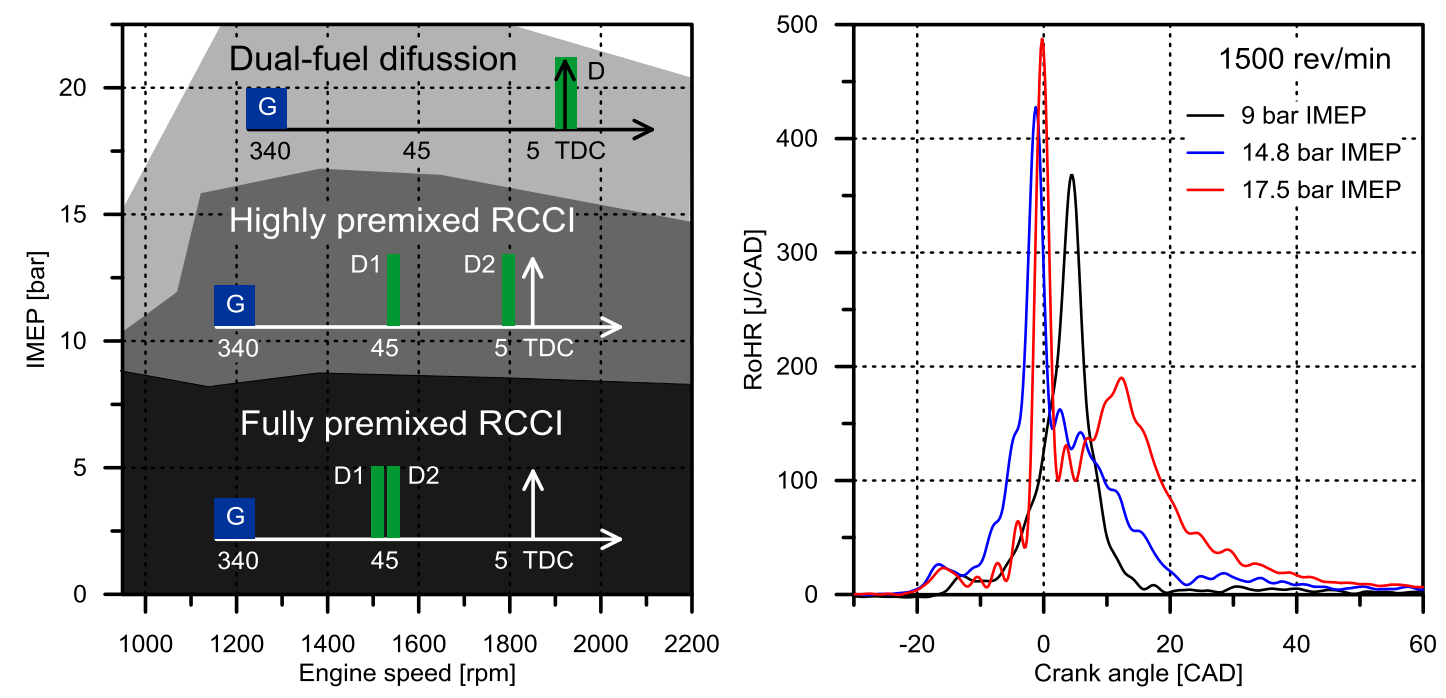

Figure 4. Injection/combustion strategies used to cover the engine map (left) and examples of the RoHR traces from each combustion strategy at $1500 \mathrm{rev} / \mathrm{min}$ (right).

\subsection{Dual-fuel emissions mapping}

The experimental procedure followed to obtain the engine maps can be summarized in the three consecutive steps shown in Figure 5, where the engine variables tuned in each step are shown in parentheses. As the figure shows, the objective of the first step is finding potential engine settings that allow stable engine operation at the desired engine load and under the constraints imposed (PRR, $P_{\max }$ and COV). Later, the second step proposes a routine to reach operating conditions that fulfill the EURO VI NOx limit together with ultra-low soot emissions. Finally, the third step aims at minimizing $\mathrm{HC}$ and CO emissions at the same time that fuel consumption is improved and NOx and soot emissions are maintained under the limits stablished. If the constraints imposed in each step are fulfilled, a fully premixed $\mathrm{RCCl}$ condition is obtained as a result (RCCI FP). If not, depending on the engine load, a highly premixed $\mathrm{RCCl}$ (RCCI HP) or a diffusive dual-fuel (D-F Dif) operating condition is reached, as explained in the combustion strategy description. 


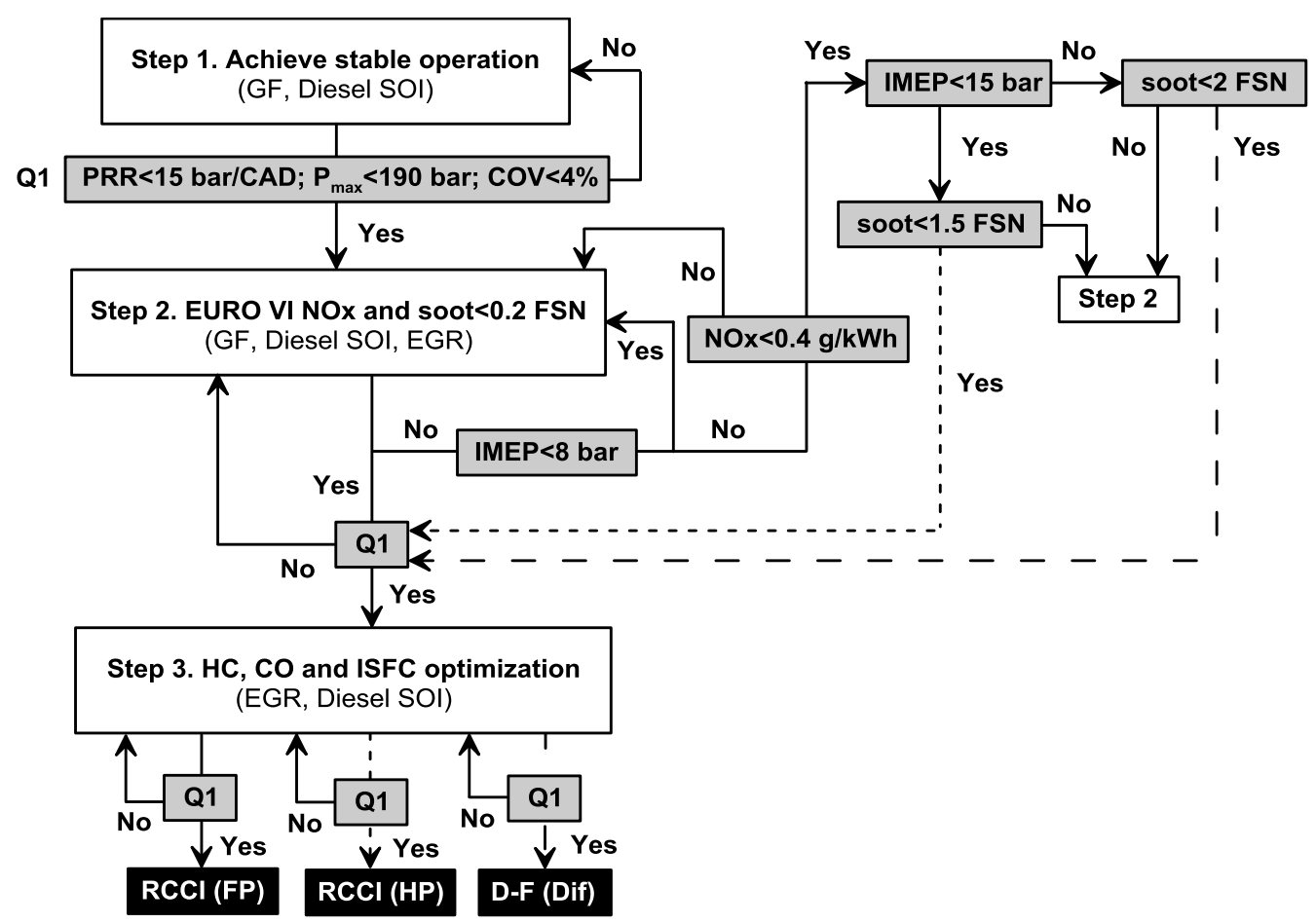

Figure 5. Experimental procedure followed to obtain the dual-fuel engine maps shown in this section.

Figure 6 shows the NOx and smoke emissions maps obtained with the combustion strategy described in the previous section. As it can be seen, this combustion strategy allows achieving engine-out NOx emissions below the EURO VI limit $(0.4 \mathrm{~g} / \mathrm{kWh})$ up to $75 \%$ load for all the engine speeds, where the fully and highly premixed $\mathrm{RCCl}$ modes are implemented. The shape of the NOx emissions map is well related with the gasoline fraction (GF) and EGR rate used (Figure 7). As can be confirmed comparing both figures, the peninsulas with the highest NOx emissions correspond to the portion of the map with the lowest GF and EGR. In this sense, increasing the direct injection fraction of diesel fuel causes locally higher equivalence ratios and higher temperatures, thus producing more NOx. Lastly, it is interesting to remark that the portion of the map between $75 \%$ and full load is mainly fulfilled with NOx levels ranging between 0.6 and $0.8 \mathrm{~g} / \mathrm{kWh}$ and some peaks of around 1.2 and $1.4 \mathrm{~g} / \mathrm{kWh}$, which supposes a drastic reduction as compared to the $10 \mathrm{~g} / \mathrm{kWh}$ typically attained with the current diesel engines at full load conditions, which are calibrated to be used with an SCR system.

The shape of the smoke emissions map is merely defined by the combustion strategy used in each portion of the map. As the combustion strategy moves from fully premixed to diffusive, i.e. from low to high load, soot emissions raise. As shown in Figure 6, the portion of the map below 10 bar IMEP ( $\mathrm{RCCl}$ mode) was completed with smoke emissions less than 0.2 FSN, which is consequence of the wide mixing time for both diesel injection pulses and the low EGR rate used in this region (Figure 7). The medium load region (up to 15 bar IMEP) was fulfilled with around 0.6 FSN of smoke in average, with peaks of 1 and $1.2 \mathrm{FSN}$ in some operating conditions. The raise in soot emissions in this portion of the map is explained by both, the switch to a less premixed strategy for the diesel fuel and the higher EGR rates used. Finally, a maximum peak of 2 FSN is observed at full load conditions (22 bar IMEP) in the high speed zone of the map, which is not dramatic considering the typical values obtained during CDC operation. 

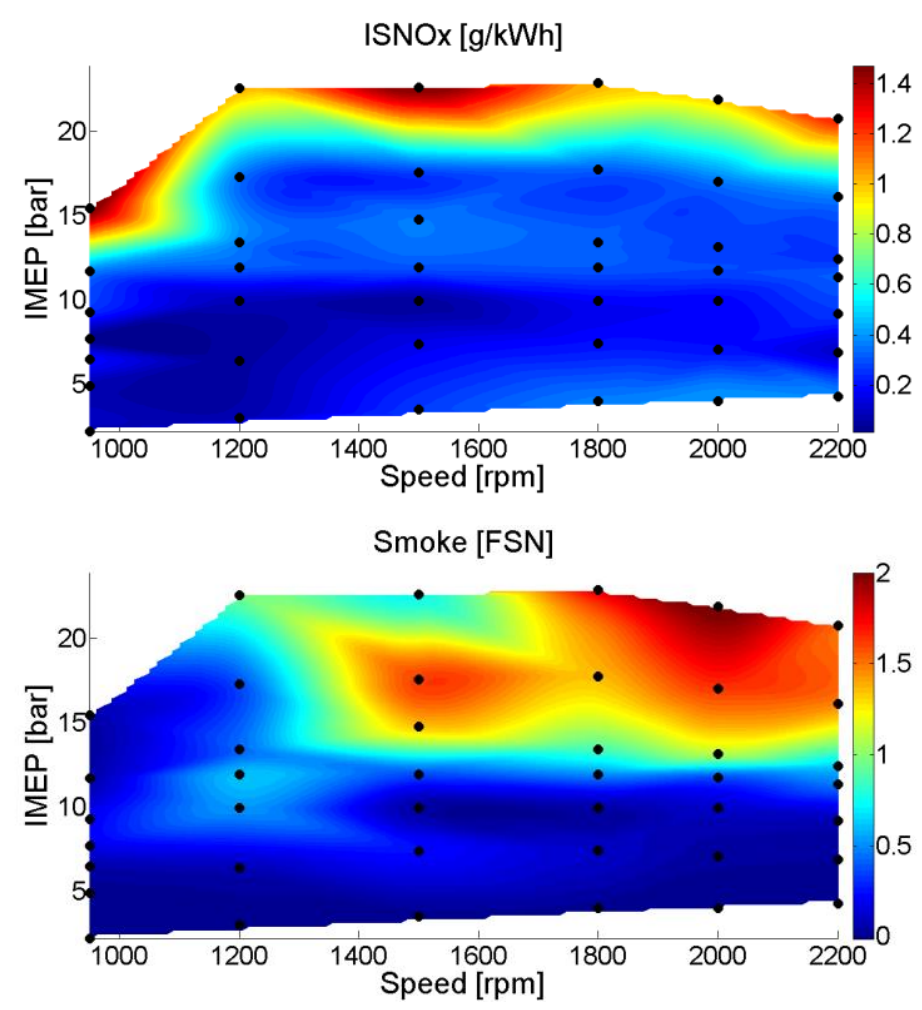

Figure 6. NOx and smoke emissions maps for the dual-fuel strategy.

The gasoline fraction was typically set to the highest value that could be achieved with the highest combustion stability and lowest $\mathrm{HC}$ emissions. As shown in Figure 7, this resulted in a minimum GF of $20 \%$ at low speed and low load to avoid excessive unburned products and combustion instabilities, increasing to nearly $80-90 \%$ in the engine map region between 5 and 10 bar IMEP for all engine speeds. At high load, it was necessary to decrease the GF to avoid excessive PRR. Regarding the EGR rate, the figure shows that it increases as the engine load increases. As it can be seen, the portion of the map up to around 8 bar IMEP was covered with only $20 \%$ of EGR rate. This is due to the use of the fully premixed RCCl strategy, which allows reaching very low NOx and soot emissions, inherently. Later, when switching to a highly premixed strategy, the EGR rate was increased up to a maximum value of $50 \%$ at 12 bar IMEP to extend the premixing time and minimize the diffusion burning of the second diesel injection. Finally, in the upper portion of the map, the EGR rate was reduced again up to values of around $30 \%$ to avoid the excessive soot emissions provoked by the diffusive dual-fuel combustion strategy.

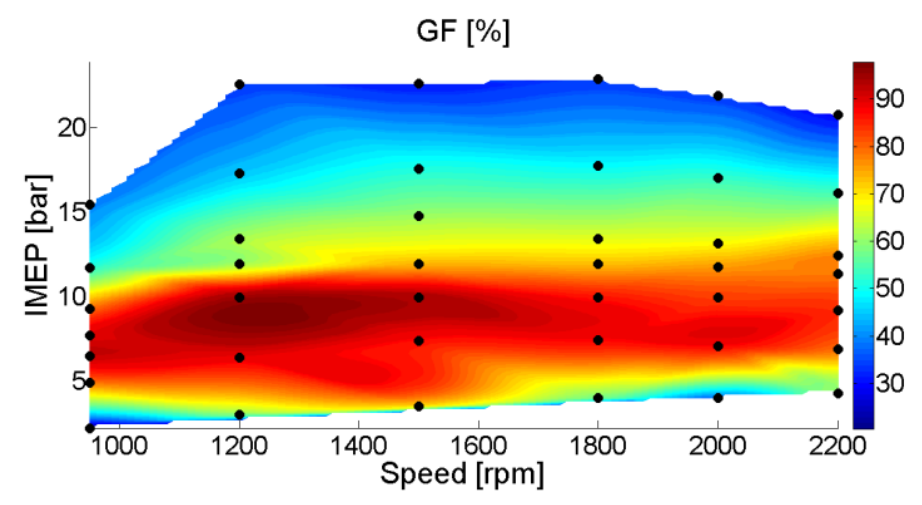




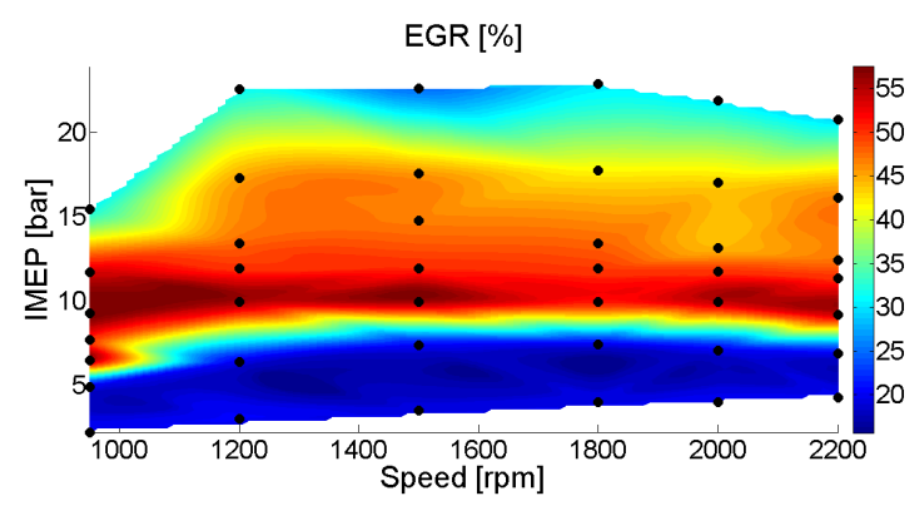

Figure 7. GF and EGR rate maps used to implement the dual-fuel strategy.

Figure 8 shows the unburned hydrocarbon $(\mathrm{HC})$ and carbon monoxide (CO) emissions maps. As it can be seen, both pollutants follow the same trend, with decreasing emission levels as load and engine speed increase. At idle conditions and low engine speeds (950$1500 \mathrm{rpm}$ ), the maximum peaks for both pollutants are found. The high amount of CO emissions can be explained looking at the maximum bulk gas temperature contour plot shown in Figure 9, where it is clear that the regions of lowest temperature correspond to those of maximum $\mathrm{CO}$ emissions levels. Considering the very low global equivalence ratio set at idle conditions (Figure 9), it can be stated that the incomplete combustion of over-lean fuel/air mixture is the dominant mechanism responsible for the $\mathrm{CO}$ emissions. Moreover, it can be seen that maximum bulk gas temperatures under $1200 \mathrm{~K}$ freeze the CO oxidation. Thus, the optimal combustion strategy will have a charge that results in bulk gas temperatures in the range of $1500 \mathrm{~K}$ to $1700 \mathrm{~K}$, where the lower temperature limit ensures complete oxidation of carbon monoxide and the upper temperature limit promotes minimal NOx formation.

The hydrocarbon emissions map is very similar to that of $\mathrm{CO}$. In this sense, maximum peaks of around $14 \mathrm{~g} / \mathrm{kWh}$ are observed at low load and low speed. Considering the equivalence ratio and the bulk gas temperature at this region, it is thought that the main precursor of $\mathrm{HC}$ emissions is the flame quenching due to the slowing down of the chemical reaction rates. Above 10 bar IMEP, very low HC emissions are observed, where global equivalence ratio is between 0.7 and 0.8 and bulk gas temperatures are above $1700 \mathrm{~K}$.

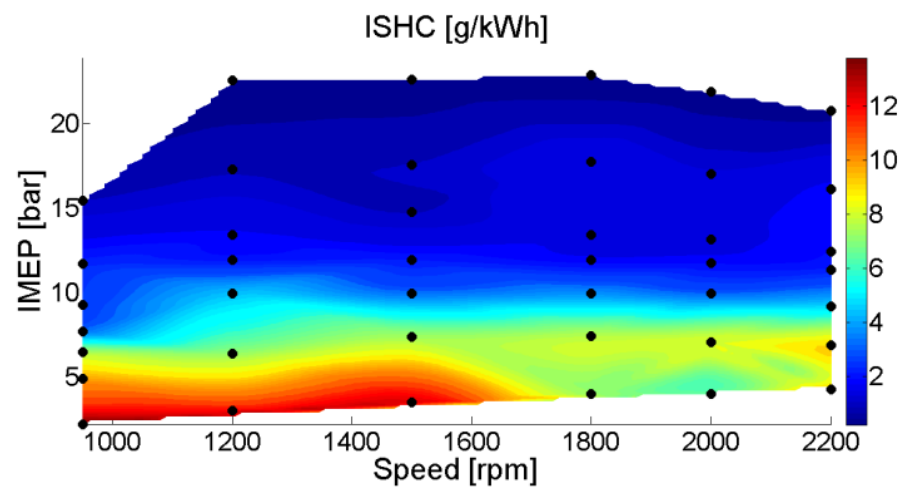




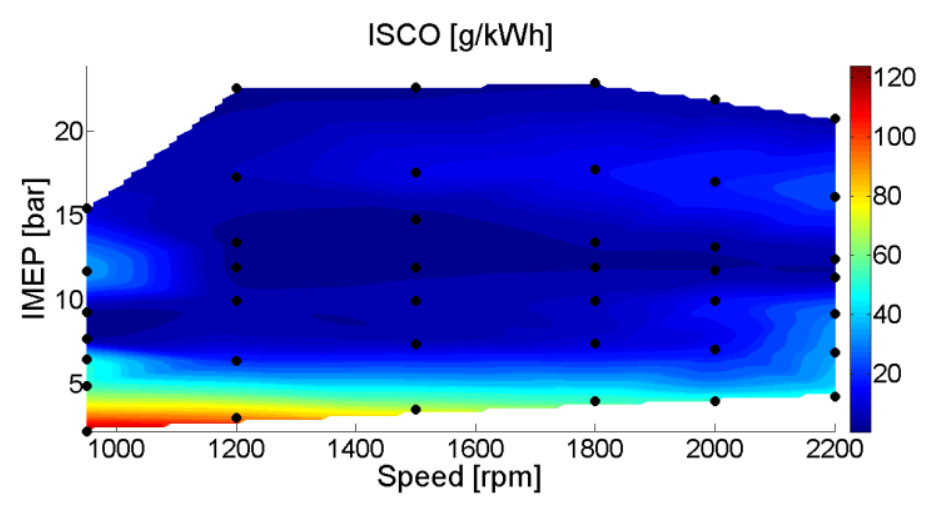

Figure 8. $\mathrm{HC}$ and $\mathrm{CO}$ emissions maps for the dual-fuel strategy.
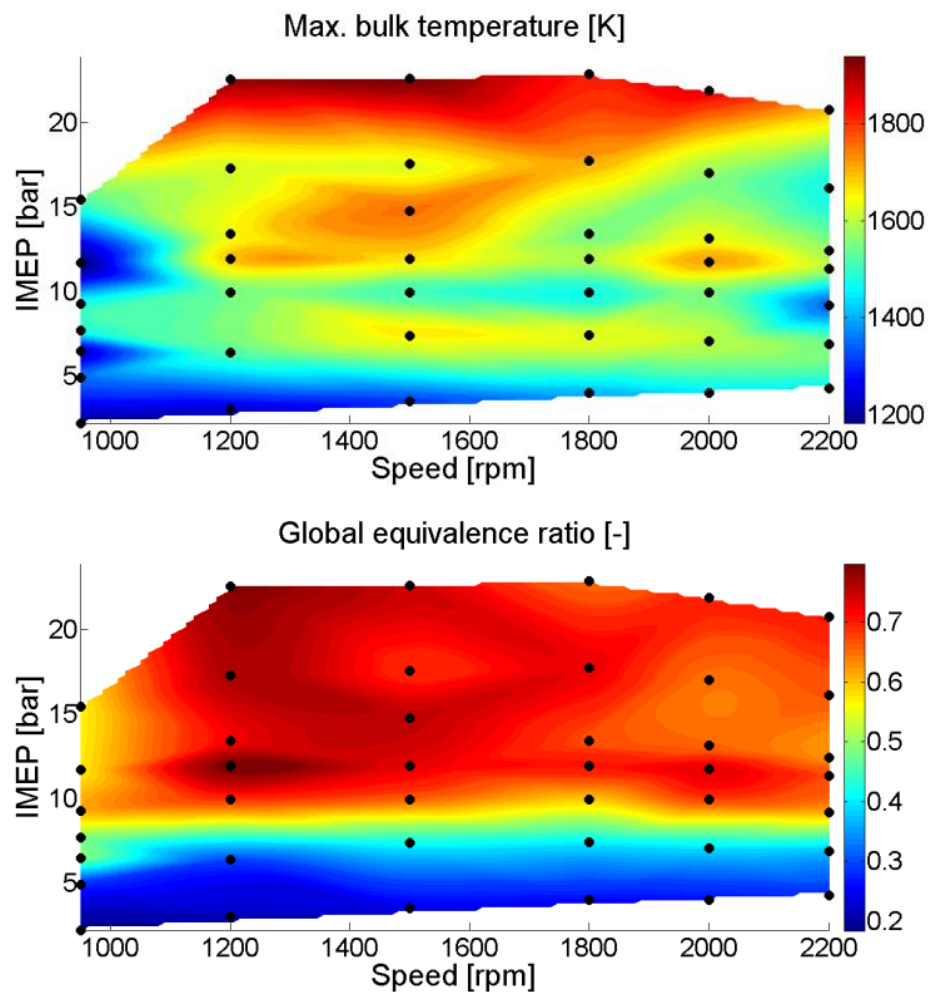

Figure 9. Maximum bulk gas temperature and global equivalence ratio map for the dual-fuel strategy.

Previous RCCl research performed by Prikhodko et al. [45] demonstrated that the chemical composition of the unburned products from RCCl operation differ notably to those from CDC. This fact resulted in a light-off temperature increase of the conventional diesel oxidation catalysts (DOC) when used to catalyze the exhaust emissions from RCCI. In particular, it was found that exhaust temperatures must be at least $300{ }^{\circ} \mathrm{C}$ to ensure an effective oxidation of $\mathrm{CO}$ and $\mathrm{HC}$ emissions, also confirming no catalyst activity for temperatures under $200{ }^{\circ} \mathrm{C}$. Taking into account this scenario, it is interesting to examine the exhaust temperature for the engine map obtained with the combustion strategy proposed in this investigation. In the light of the results shown in Figure 10, it is possible to state that the operation of the DOC could be compromised only in the region below 4 bar IMEP and $1500 \mathrm{rpm}$. However, considering the great NOx margin up to the EURO VI limit, this portion of the map could be refined in further optimization steps to increase the exhaust temperature. From 4 to 8 bar IMEP the 
catalyst reactions are expected to start, presuming an effective oxidation above 8 bar IMEP, where the exhaust temperatures are over $300^{\circ} \mathrm{C}$ for all the engine speeds.

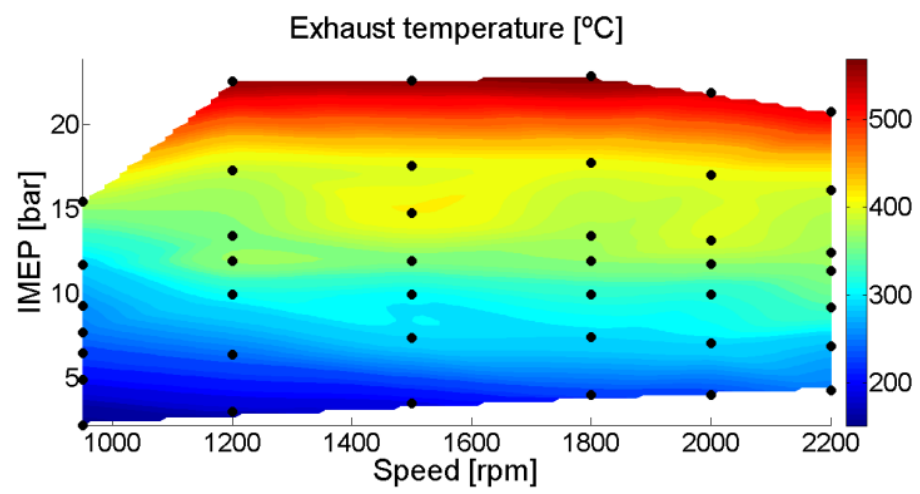

Figure 10. Exhaust temperature map for the dual-fuel strategy.

\subsection{Dual-fuel vs stock CDC operation}

This section evaluates the potential of the dual-fuel combustion strategy proposed in section 3.1. To do this, the engine maps presented in the previous section are compared against the ones obtained with the engine operating in conventional diesel combustion, using the ECU settings and the stock hardware (CR 17.5:1). For the sake of clarity, the results are depicted as contour plots of the difference between the two data sets (RCCI$\mathrm{CDC}$ in all the cases). This approach gives a clear overview about the general trends and the possible potential of the dual-fuel concept proposed in this paper over a current state of the art diesel engine.

Figure 11 shows the NOx and soot emissions differences between RCCl and CDC. As it can be seen, $\mathrm{RCCl}$ provides a NOx reduction ranging from $75 \%$ to $98 \%$ as compared to $\mathrm{CDC}$ operation in all the engine map, showing the maximum peaks of NOx reduction in the low engine speed region. This results represent a good opportunity to reduce the urea fluid necessary to meet the EURO VI regulation with the current diesel engines. Regarding smoke emissions, they are greatly improved with $\mathrm{RCCl}$ in the region below 10 bar IMEP and above $1800 \mathrm{rpm}$. In the low speed region, the improving is only observed at very low loads. In the rest of the map, the dual-fuel concept shows higher smoke results than CDC. This is due to the conjunction of two facts, the very low CDC smoke levels achieved with the EURO VI ECU calibration (at the expense of producing high amount of NOx emissions) and the relatively high smoke emissions coming from the dual-fuel diffusion combustion strategy used in this portion of the map. In spite of that, it is interesting to remark that smoke emissions with dual-fuel are not dramatic (Figure 6), and it is expected to obtain low accumulated emissions if a stationary homologation cycle were conducted. 

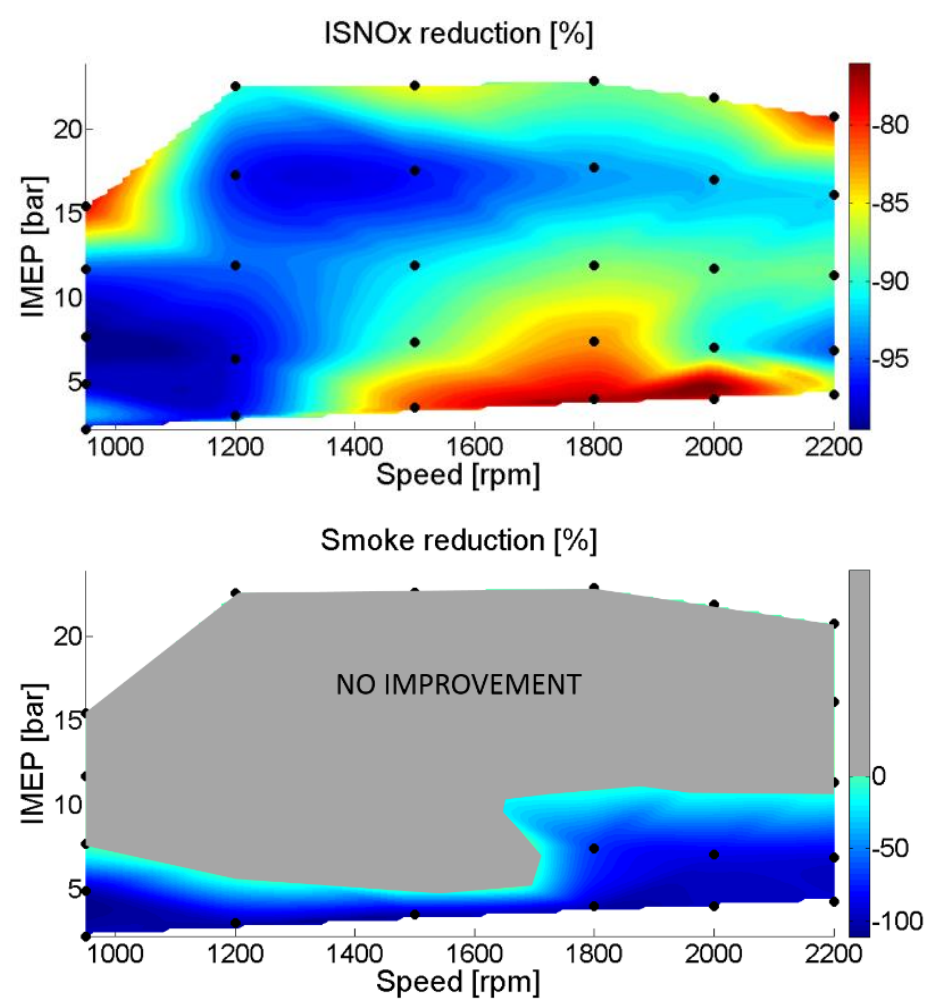

Figure 11. NOx and smoke emissions reduction with the dual-fuel strategy versus CDC.

Figure 12 shows the combustion efficiency difference, which computes both $\mathrm{CO}$ and $\mathrm{HC}$ emissions as shown in Equation 1. As the map reveals, the dual-fuel strategy proposed leads to lower combustion efficiency than CDC in all the engine map. This will suppose a source of inefficiency of the concept, mainly at low load, but it is interesting to note that the major contribution to the incomplete combustion is coming from CO emissions, which is desirable because it has typically four times less energetic content than HC. Nevertheless, it is possible to see that the region above 8 bar IMEP shows combustion efficiency penalties less than $4 \%$, which is not dramatic considering that $\mathrm{RCCl}$ combustion mode is capable of counteracting this losses by means of the heat transfer reduction and the combustion process improvement.

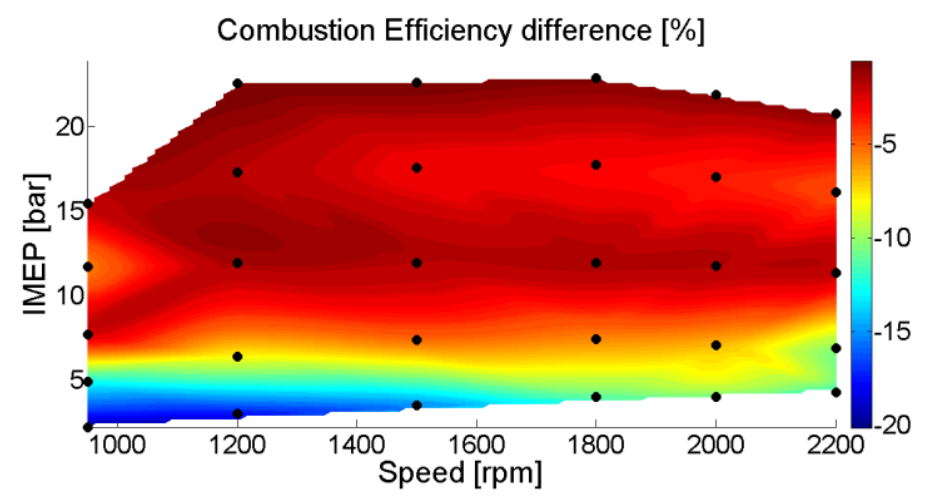

Figure 12. Combustion efficiency difference between $\mathrm{RCCl}$ and $\mathrm{CDC}$.

Finally, Figure 13 shows the corrected gross indicated efficiency (GIE) difference between $\mathrm{RCCl}$ and $\mathrm{CDC}$. The current diesel engines are calibrated relying on the injection of urea fluid in the exhaust gas stream to increase the SCR efficiency and meet the EURO VI NOx emissions limit. In the case of the VOLVO D5K240 engine, the urea fluid is injected 
upwards the SCR using an air-assisted dosing system. To do so, a control module calculates the urea dosing rate needed based on various engine parameters, and the exact quantity of urea is mixed with air from the vehicle compressed air system. Then, a single-hole injector nozzle injects the urea-air mixture in the center of the exhaust stream. Thus, in order to perform a more realistic comparison between dual-fuel and CDC operation, an additional "fuel" consumption should be considered in the part of the maps that do not fulfill the NOx emissions limit in-cylinder. This will penalize the CDC operation in a greater portion of the map, since in the case of dual-fuel, the EURO VI NOx emissions limit is achieved up to $75 \%$ load. The urea necessary to reduce $1 \mathrm{~g} / \mathrm{kWh}$ of NOx emissions can be estimated as $1 \%$ of the fuel consumption [46], so that the urea required to reduce the engine-out NOx emissions up to the EURO VI target can be estimated as shown in Equation 2. Considering this, the GIE for CDC can be corrected on a cost-basis as stated in Equation 3, which supposes the same price for both fluids. This correction is also applied to the GIE map of $\mathrm{RCCl}$ in the region in which the concept does not fulfill the EURO VI limit by itself (from 75\% to full load), as shown in Equation 4.

$$
\begin{gathered}
m_{\text {urea }}=\left(N O x_{\text {engine-out }}-N O x_{\text {EUROVI }}\right) \cdot 0.01 \cdot m_{\text {diesel }} \\
G I E_{C D C_{-} \text {corr }}=\frac{W_{i}}{\left(m_{\text {urea }}+m_{\text {diesel }}\right) \cdot L H V_{\text {diesel }}} \\
G I E_{R C C I \text { corr }}=\frac{W_{i}}{\left(m_{\text {urea }}+m_{\text {diesel }}\right) \cdot L H V_{\text {diesel }}+m_{\text {gas }} \cdot L H V_{\text {gas }}}
\end{gathered}
$$

Looking at the Figure 13, it is observed that the dual-fuel concept improves the engine efficiency over the whole engine map, showing an improvement equal or greater than $3 \%$ in all the conditions in except of two conditions. As a general trend, the efficiency gain with $\mathrm{RCCl}$ increases as engine load increases, achieving efficiency improvements up to $7 \%$ compared to CDC at high load conditions, which confirm the clear benefits of the dual-fuel strategy proposed versus conventional diesel combustion.

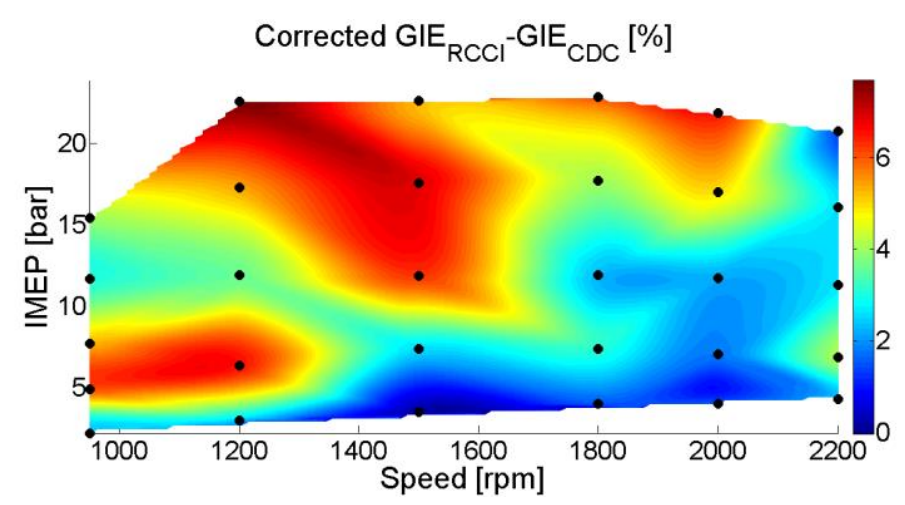

Figure 13. Corrected gross indicated efficiency difference between RCCI and CDC. The raw GIE maps have been corrected to account the urea injected in the exhaust system.

\section{Conclusions}

The present work has investigated the emissions and performance potential of an optimized duel-fuel strategy versus CDC in a medium-duty EURO VI diesel engine fueled with regular gasoline and diesel fuels. For this purpose, a dual-fuel strategy that changes as a function of the engine load has been developed and several performance and emissions maps have been obtained following a dedicated testing procedure. 
The dual-fuel combustion strategy proposed changes as a function of the engine load. At low loads, a fully premixed RCCl strategy is applied, which allows achieving ultra-low NOx and soot emissions simultaneously. As load increases, a highly premixed RCCI strategy is proposed. In this case, the injection timing of the second diesel injection is delayed towards TDC, which is necessary to minimize the knocking tendency. This strategy leads to NOx emissions below the EURO VI limit, but soot emissions are higher than with the previous strategy due to the richer equivalence ratios obtained at the autoignition. Finally, to complete the engine map between $75 \%$ and full load, a diffusive dual-fuel combustion strategy is applied. This is necessary to avoid the excessive pressure rise rates appearing during premixed combustion with high quantities of homogeneously mixed gasoline. In this case, NOx and soot emissions are higher than with the other strategies, but the emissions levels found are not dramatic.

The analysis of the engine-out emissions of the dual-fuel concept proposed has shown that the low load low speed region should be optimized to minimized $\mathrm{CO}$ and $\mathrm{HC}$ emissions and increase the exhausts temperatures to ensure the effectiveness of the DOC. This work is feasible since in this portion of the map it was found a great margin of NOx emissions to the EURO VI limit, and therefore in-cylinder temperatures can be increased. The comparison versus CDC has revealed that this dual-fuel strategy has a great potential to reduce the NOx emissions of compression ignition engines in all the engine map, with a simultaneous reduction of smoke emissions in the low load region. Above 5 bar IMEP, the smoke emissions were found to be greater than those of the EURO VI diesel engine, but the majority of the engine map was fulfilled with levels below 1 FSN. Finally, one important finding of the study is that, if the urea fuel is computed as additional fuel penalty, the dual-fuel concept shows indicated efficiencies greater than $3 \%$ versus $C D C$ in all the engine map, showing some peninsulas in which the improvement arrives up to $7 \%$.

\section{Acknowledgments}

This investigation has been funded by VOLVO Group Trucks Technology. The authors also acknowledge the Spanish economy and competitiveness ministry for partially supporting this research (HiReCo TRA2014-58870-R). The predoctoral contract of the author J. Monsalve-Serrano (FPI-S2-2015-1531) is granted by the Programa de Apoyo para la Investigación y Desarrollo (PAID) of the Universitat Politècnica de València.

\section{References}

[1] Johnson TV. Vehicular Emissions in Review. SAE International Journal of Engines, Vol. 5, pp 216-234, 2012.

[2] Fino D, Bensaid S, Piumetti M, Russo N. A review on the catalytic combustion of soot in Diesel particulate filters for automotive applications: From powder catalysts to structured reactors. Applied Catalysis A: General, Vol. 509, pp 75-6, 2016.

[3] Lawler B, Splitter D, Szybist J, Kaul B. Thermally Stratified Compression Ignition: A new advanced low temperature combustion mode with load flexibility. Applied Energy, Vol. 189, pp 122-132, 2017.

[4] Imtenan S, Varman M, Masjuki HH, Kalam MA, Sajjad H, Arbab MI, Rizwanul Fattah IM. Impact of low temperature combustion attaining strategies on diesel engine emissions for diesel and biodiesels: A review. Energy Conversion and Management, Vol. 80, pp 329-356, 2014. 
[5] Yousefi A, Gharehghani A, Birouk M. Comparison study on combustion characteristics and emissions of a homogeneous charge compression ignition $(\mathrm{HCCl})$ engine with and without pre-combustion chamber. Energy Conversion and Management, Vol. 100, pp. 232-241, 2015.

[6] Komninos NP. Assessing the effect of mass transfer on the formation of $\mathrm{HC}$ and $\mathrm{CO}$ emissions in $\mathrm{HCCl}$ engines, using a multi-zone model. Energy Conversion and Management, Vol. 50 (5), pp 1192-1201, 2009.

[7] Bessonette P W, Schleyer C H, Duffy K P, Hardy W L, Liechty M P. Effects of fuel property changes on heavy-duty HCCl combustion. SAE paper 2007-01-0191, 2007.

[8] Xie $\mathrm{H}$, Li L, Chen T, Zhao H. Investigation on gasoline homogeneous charge compression ignition $(\mathrm{HCCl})$ combustion implemented by residual gas trapping combined with intake preheating through waste heat recovery. Energy Conversion and Management, Vol. 86, pp 8-19, 2014.

[9] Cinar C, Uyumaz A, Solmaz H, Topgul T. Effects of valve lift on the combustion and emissions of a $\mathrm{HCCl}$ gasoline engine. Energy Conversion and Management, Vol. 94, pp 159-168, 2015.

[10] Mahrous A-F, Potrzebowski A, Wyszynski ML, Xu HM, Tsolakis A, Luszcz P. A modelling study into the effects of variable valve timing on the gas exchange process and performance of a 4-valve DI homogeneous charge compression ignition ( $\mathrm{HCCl}$ ) engine. Energy Conversion and Management, Volume 50 (2), pp 393-398, 2009.

[11] Yousefi A, Madjid Birouk M. Fuel suitability for homogeneous charge compression ignition combustion. Energy Conversion and Management, Vol. 119, pp 304-315, 2016.

[12] López JJ, García-Oliver JM, García A, Domenech V. Gasoline effects on spray characteristics, mixing and auto-ignition processes in a $\mathrm{Cl}$ engine under Partially Premixed Combustion conditions. Applied Thermal Engineering, Vol. 70 (1), pp 9961006, 2014.

[13] Zhang X, Wang H, Zheng Z, Reitz R, Yao M. Experimental investigations of gasoline partially premixed combustion with an exhaust rebreathing valve strategy at low loads. Applied Thermal Engineering, Vol. 103, pp 832-841, 2016.

[14] Kalghatgi G, Risberg P, Angstrom H. Advantages of fuels with high resistance to autoignition in late-injection, low-temperature, compression ignition combustion. SAE Trans., 2006, 115(4), 623-634.

[15] Liu $H$, Yao M, Zhang B, Zheng Z. Effects of inlet pressure and octane numbers on combustion and emissions of a homogeneous charge compression ignition $(\mathrm{HCCl})$ engine. Energy and Fuels, 2008, 22(4), 2207-2215.

[16] Christensen M, Hultqvist A, Johansson B. Demonstrating the multi-fuel capability of a homogeneous charge compression ignition engine with variable compression ratio. SAE paper 1999-01-3679, 1999.

[17] Benajes J, García A, Domenech V, Durrett R. An investigation of partially premixed compression ignition combustion using gasoline and spark assistance. Applied Thermal Engineering, Volume 52, Issue 2, 15 April 2013, Pages 468-477.

[18] Benajes J, García A, Tormos B, Monsalve-Serrano J. Impact of Spark Assistance and Multiple Injections on Gasoline PPC Light Load. SAE Int. J. Engines 7(4):2014, doi:10.4271/2014-01-2669.

[19] Desantes JM, Payri R, García A, Monsalve Serrano J. Evaluation of Emissions and Performances from Partially Premixed Compression Ignition Combustion using 
Gasoline and Spark Assistance. SAE Technical Paper 2013-01-1664, 2013, doi:10.4271/2013-01-1664.

[20] Benajes J, Molina S, García A, Monsalve-Serrano J, Durrett R. Conceptual model description of the double injection strategy applied to the gasoline partially premixed compression ignition combustion concept with spark assistance. Applied Energy, Volume 129, 15 September 2014, Pages 1-9.

[21] Benajes J, Molina S, García A, Monsalve-Serrano J, Durrett R. Performance and engine-out emissions evaluation of the double injection strategy applied to the gasoline partially premixed compression ignition spark assisted combustion concept. Applied Energy, Volume 134, 1 December 2014, Pages 90-101.

[22] Salahi M, Esfahanian V, Gharehghani A, Mirsalim M. Investigating the reactivity controlled compression ignition ( $\mathrm{RCCl}$ ) combustion strategy in a natural gas/diesel fueled engine with a pre-chamber. Energy Conversion and Management, Vol. 132, pp 40-53, 2017.

[23] Benajes J, Molina S, García A, Monsalve-Serrano J. Effects of low reactivity fuel characteristics and blending ratio on low load $\mathrm{RCCl}$ (reactivity controlled compression ignition) performance and emissions in a heavy-duty diesel engine. Energy, Volume 90, October 2015, Pages 1261-1271.

[24] UW Splitter D, Hanson R, Kokjohn S, Wissink M, Reitz R. Injection Effects in Low Load RCCI Dual-Fuel Combustion. SAE Technical Paper 2011-24-0047, 2011, doi:10.4271/2011-24-0047.

[25] Benajes J, Pastor JV, García A, Monsalve-Serrano J. The potential of RCCl concept to meet EURO VI NOx limitation and ultra-low soot emissions in a heavy-duty engine over the whole engine map. Fuel, Volume 159, November 2015, Pages 952-961.

[26] Fraioli V, Mancaruso E, Migliaccio M, Vaglieco B. Ethanol effect as premixed fuel in dual-fuel $\mathrm{Cl}$ engines: Experimental and numerical investigations. Applied Energy, Vol. 119, Pages 394-404, 2014.

[27] Benajes J, Molina S, García A, Monsalve-Serrano J. Effects of Direct injection timing and Blending Ratio on RCCl combustion with different Low Reactivity Fuels. Energy Conversion and Management, Volume 99, July 2015, Pages 193-209.

[28] Ma S, Zheng Z, Liu H, Zhang Q, Yao M. Experimental investigation of the effects of diesel injection strategy on gasoline/diesel dual-fuel combustion. Applied Energy, Vol. 109, pp 202-212, 2013.

[29] Kokjohn S L, Hanson R M, Splitter D A, Reitz R D. Fuel reactivity controlled compression ignition (RCCl): a pathway to controlled high-efficiency clean combustion, International Journal of Engine Research, 2011. Volume 12, June 2011, Pages 209-226.

[30] Nazemi M, Shahbakhti M. Modeling and analysis of fuel injection parameters for combustion and performance of an RCCl engine. Applied Energy, Vol. 165, pp 135150, 2016. 
[31] Desantes JM, Benajes J, García A, Monsalve-Serrano J. The Role of the In-Cylinder Gas Temperature and Oxygen Concentration over Low Load RCCl Combustion Efficiency. Energy, Volume 78, December 2014, Pages 854-868

[32] Tong L, Wang H, Zheng Z, Reitz R, Yao M. Experimental study of RCCl combustion and load extension in a compression ignition engine fueled with gasoline and PODE. Fuel, Vol. 181, pp 878-886, 2016.

[33] Curran S, Gao Z, Wagner R. Reactivity Controlled Compression Ignition Drive Cycle Emissions and Fuel Economy Estimations Using Vehicle Systems Simulations with E30 and ULSD. SAE Int. J. Engines 7(2):2014, doi:10.4271/2014-01-1324.

[34] Benajes J, García A, Monsalve-Serrano J, Balloul I, Pradel G. An assessment of the dual-mode reactivity controlled compression ignition/conventional diesel combustion capabilities in a EURO VI medium-duty diesel engine fueled with an intermediate ethanol-gasoline blend and biodiesel. Energy Conversion and Management, Volume 123, July 2016, Pages 381-391.

[35] Benajes J, García A, Monsalve-Serrano J, Balloul I, Pradel G. Operational Limits Assessment of $\mathrm{RCCl}$ Combustion in a High Compression Ratio Medium-Duty Diesel Engine using near-term available Biofuels. THIESEL 2016 Conference on Thermo- and Fluid Dynamic Processes in Direct Injection Engines, 2016.

[36] Benajes J, Pastor JV, García A, Boronat V. A RCCl operational limits assessment in a medium duty compression ignition engine using an adapted compression ratio. Energy Conversion and Management, Volume 126, 2016, Pages 497-508.

[37] Splitter D, Wissink M, Kokjohn S, Reitz R. Effect of Compression Ratio and Piston Geometry on RCCI Load Limits and Efficiency. SAE Technical Paper 2012-01-0383, 2012, doi:10.4271/2012-01-0383.

[38] Benajes J, García A, Pastor JM, Monsalve-Serrano J. Effects of piston bowl geometry on Reactivity Controlled Compression Ignition heat transfer and combustion losses at different engine loads. Energy, Volume 98, March 2016, Pages 64-77.

[39] Benajes J, Pastor JV, García A, Monsalve-Serrano J. An experimental investigation on the Influence of piston bowl geometry on $\mathrm{RCCl}$ performance and emissions in a heavy-duty engine. Energy Conversion and Management, Volume 103, October 2015, Pages 1019-1030.

[40] Yu S, Zheng M. Ethanol-diesel premixed charge compression ignition to achieve clean combustion under high loads. Proceedings of the Institution of Mechanical Engineers, Part D: Journal of Automobile Engineering, 2015. doi: 10.1177/0954407015589870.

[41] Klos D, Janecek D, Kokjohn S. Investigation of the Combustion Instability-NOx Tradeoff in a Dual Fuel Reactivity Controlled Compression Ignition (RCCI) Engine. SAE Int. J. Engines 8(2):2015, doi:10.4271/2015-01-0841.

[42] Agarwal A., Pandey A., Gupta A., Aggarwal S., Kushari A. Novel Combustion Concepts for Sustainable Energy Development. Springer. ISBN 978-81-322-2211-8. 
[43] Payri F, Olmeda P, Martín J, García A. A complete OD thermodynamic predictive model for direct injection diesel engines. Applied Energy, Volume 88, Issue 12, December 2011, Pages 4632-4641.

[44] Payri F, Olmeda P, Martin J, Carreño R. A New Tool to Perform Global Energy Balances in DI Diesel Engines. SAE Int. J. Engines 7(1):2014, doi:10.4271/2014-010665.

[45] Prikhodko V, Curran S, Parks J, Wagner R. Effectiveness of Diesel Oxidation Catalyst in Reducing $\mathrm{HC}$ and CO Emissions from Reactivity Controlled Compression Ignition. SAE Int. J. Fuels Lubr. 6(2):329-335, 2013, doi:10.4271/2013-01-0515.

[46] Johnson T. Diesel Emissions in Review. SAE Int. J. Engines, 4(1):143-157, 2011, doi:10.4271/2011-01-0304.

\section{Abbreviations}

ASTM: American Society for Testing and Materials

ATDC: After Top Dead Center

CAD: Crank Angle Degree

CA50: Crank angle at 50\% mass fraction burned

CDC: Conventional Diesel Combustion

CO: Carbon Monoxide

CR: Compression Ratio

DI: Direct Injection

DPF: Diesel Particulate Filter

ECU: Electronic Control Unit

EGR: Exhaust Gas Recirculation

EVO: Exhaust Valve Open

FSN: Filter Smoke Number

HC: Hydro Carbons

$\mathrm{HCCl}$ : Homogeneous Charge Compression Ignition

IMEP: Indicated Mean Effective Pressure

IVC: Intake Valve Close

IVO: Intake Valve Open

LTC: Low Temperature Combustion

MCE: Multi Cylinder Engine

OEM: Original Equipment Manufacturer 
ON: Octane Number

PFI: Port Fuel Injection

PPC: Partially Premixed Charge

PRR: Pressure Rise Rate

RCCl: Reactivity Controlled Compression Ignition

RoHR: Rate of Heat Release

SOC: Start of Combustion

SCE: Single Cylinder Engine

SCR: Selective Catalytic Reduction 